\title{
Nanocomposites produced by SOL-GEL and Melt Mixing Methods
}

\author{
Hamed Ahari ${ }^{1 *}$, Solmaz Barani², Saeed Bazgir ${ }^{3}$ \\ 1Department of Food Science and Technology, Science and Research Branch, Islamic Azad University \\ Tehran, Iran \\ dr.h.ahari@gmail.com* corresponding author \\ 2Department of Food Science and Technology, Science and Research Branch, Islamic Azad University \\ Tehran, Iran \\ 3Department of Engineering, Science and Research Branch, Islamic Azad University \\ Tehran, Iran
}

\begin{abstract}
In this study, LDPE / Ag / Tio2 nanocomposite films were prepared by dissolution and melt mixing methods with percentages of $1 \%, 3 \%$ and $5 \%$ of nano silver and $0.5 \%, 1.5 \%$ and $2.5 \%$ of titanium dioxide, and then the anti- The bacterial production of films produced by the inhibition test of the bacterial indicators of Staphylococcus aureus, Escherichia coli 0157, Candida albicans and Spraygyl Niger was investigated, and then the shelf-life of the Sufan fish with the coverage of various films produced on days 0-5-10-15 and 20 were evaluated. The presence of nanomaterials was confirmed by FE-SEM testing. The results of the study showed that the film produced by melt mixing method compared with the sol-gel method significantly increased the diameter of the E. coli spp. Escherichia coli 0157 , Staphylococcus aureus, Candida albicans and Spraygyl Niger, as well as the results of the analysis of the variance effects of different concentrations of nanoparticles Silver and titanium dioxide on growth retardation of Escherichia coli 0157 and Staphylococcus aureus, Candida albicans and Escherichios Niger $(\mathrm{P}<0.05)$. According to these results, the film produced by mixing the molten mixture with 5 wt.\% Silver and $2.5 \mathrm{wt}$.\% Of dioxide The highest titanium and control treatment had the lowest non-aqueous diameter D, respectively. It was also shown in microbiological analysis that the highest species of Staphylococcus aureus and then Escherichia coli 0157 and then Candida albicans and then Aspergillus niger showed sensitivity to the prepared nanocomposites, respectively. The results of this study in relation to the storage time of the Souf fish showed that, from the day of February to the 20th day, the film produced by the melt mixing method with $5 \mathrm{wt} . \%$ Silver and $2.5 \mathrm{wt}$.\% Titanium dioxide decreased significantly (0.05> P) shows the logarithmic growth rate of aerobic mesophilic bacteria, Cold and Enterobacteriaceae.
\end{abstract}

Keywords: Nanocomposites, LDPE, Melt Mixing Methods, TiO2.

\section{Introduction}

Food packaging industry grew up as well as innovation of nano material technology along with the altering nutritional habits of consumers in response to machinery living [3]. Nowadays, packaging has been known as one of the largest industry in the world and it shows about $2 \%$ of Gross National Product (GNP) especially is likely in developed countries [1]. Nanotechnology is extremely an interdisciplinary science utilizing of interests that their dimensions are less than $100 \mathrm{~nm}$. Nanopackaging gives protection to food products during storage and transportation from undesirable conditions, such as bacteria growth [2]. Nanopackaging along with bactericidal characteristics can be effective to increase the shelf-life of the food product ensuring food safety and consumer protection [3].

It is well known that inorganic anti-pathogenic compounds are usually supplemented to the polymers by melt mixing or other processes in the ultra-fine phase dimension of dispersion behavior [4] of nano scale filler in polymer medium, of which some researchers utilized transmission electron microscopy (TEM) to observe this process at higher magnification [5]. This character gives a substantial character in nanocomposites to prevent the growth of pathogens and colonization of polymers [6].

Among the nanocomposites, Titanium dioxide (TiO2), which is a photocatalyst has been effectively applied to tap water to inactivate the bacteria. TiO2 as distinctive semiconductor photocatalyst can be play a role as an anti-pathogenic agent. The results showed that the LDPE-TiO2 nanocomposite films could be efficiently degraded under UV or sunlight radiance [7]. Numerous of electron-hole will be made on $\mathrm{TiO} 2$, and the $\mathrm{OH}^{-}$, reactive oxygen species (ROS) and absorbed water on the exterior of $\mathrm{TiO} 2$ will be radicalized While $\mathrm{TiO} 2$ introduced to photons with energy larger than the band gap of $\mathrm{TiO} 2$. 
Accordingly, Performed Hydroxyl $(\mathrm{OH})$ can attaches the pathogens and inactivate them [5] through degrading the organic components by oxidizing the $\mathrm{C}-\mathrm{H}$ bonds in the polyunsaturated phospholipid constituent of the cell wall of bacteria [8,9]. Whole these three forms of ROS release by reaction of TiO2. TiO2-covered thin layers could diminish the microbial contamination on the surface of food products [10]. Mihaly Cozmuta, et al. [11] studied the packaging of Ag/TiO2 nanocomposite prepared by solvent method to increase durability of bread and [12] examined the microbiological properties of titanium dioxide and silver $(1 \%, 3 \%$, and $5 \%$ ) nanocomposite coatings on dry sausages.. Nano particles (NP) have shown different characteristics against microbes. CuONPs showed to be more effective against E. Coli and Staphylococcus aureus but less effective against Bacillus subtilis [13]. TiO2 incorporate with silver ( $\mathrm{TiO} 2$-Ag-NPs) were experimented against Gram-negative bacteria, Gram-positive bacteria and different fungi [14]. Scientists $[15,16]$ showed the ability of Ag-NPs to discharge Ag+ is essential to inactivate bacterial activity. Yamanaka, et al. [17] showed Ag+ infiltrates into E. Coli and diminish crucial enzymes through attaching with the thiol groups result in inhibition of DNA replication and death of bacteria.

Pikeperch (Sander lucioperca) is a species of fish isolated from freshwater and brackish habitats in zone of Eurasia particularly distributed in Caspian Sea [18]. This species is one of the top ranks of commercial species found in north of Iran.

In this study, LDPE/Ag/Tio2 nanocomposite films were prepared through the solvent and melt mixing with percentages of $1 \%, 3 \%$ and $5 \%$. The antibacterial activity of the produced films were assessed against Staphylococcus aureus, Escherichia coli, Candida albicans and Aspergillus flavus using the Agar disk-diffusion test and measuring the diameters of inhibition zone. And finally, the shelf-life of Sander lucioperca fish, covering all types of produced films, was evaluated on days 0-5$10-15$ and 20 days.

\section{Materials and Methods \\ 2.1. Materials}

\subsubsection{Treatments}

According to our experiment, susceptibility of the pathogens was examined against 7 groups of LDPE, which was incorporate with different percent of $\mathrm{Ag}^{+} / \mathrm{TiO} 2$. The first group was assigned as control $\left(\mathrm{S}_{1}\right)$, which its film was produced exactly with LDPE, 3 films $\left(\mathrm{S}_{2}, \mathrm{~S}_{3}\right.$ and $\mathrm{S}_{4}$ ) produced through the melt-mixing method with defined concentrations (Tables 1) and 3 other films $\left(S_{5}, S_{6}\right.$ and $\left.S_{7}\right)$, which produced through the Sol-Gel method (Table 2). These treatments were assessed through the 2 methods. At the first method, they exposed to 4 selected microbes, which describe at the following paragraphs, using the diffusion disc method and at the second method they used as fish coverage-films to examine the shelf-life of the fish during the experiment.

\subsection{Nanocomposite Preparing: Melt Mixing}

The melt mixing experiment was carried out in the Polymer Research Institute of Iran and the manufacturing method was based on the studies of Oliani, et al. [19]. At first, the percentage and amount of materials were calculated according to Table 1 and weighed by a digital scale with accuracy of 0.1 . The LDPE pellets were mixed with Irganox 1010 in a rotary mixer and kept the mixture at same condition for $24 \mathrm{~h}$. In addition to AgNPs, it was then added in to a twin-screw extruder (Clextral, France) based the volumes presents in table 1.

The bayonet switched on the twin screw, set to 5 the thermal regions (150-165-170-175-180 ${ }^{\circ} \mathrm{C}$, respectively), $20 \mathrm{rpm}$ speed and the film production with a thickness of $0.05 \mathrm{~mm}$ was subsequently processed. After, the film (Fig. 1) was taken out from the extruder; an aluminum foil was drawn around the film to avoid direct contact with the light.

Table 1: Percentage and weight of film ingredients of 4 treatments used in melt mixing method. 


\begin{tabular}{|c|c|c|c|c|}
\hline & \multicolumn{4}{|c|}{ Percent of purity } \\
\hline & $\mathrm{S} 1$ & $\mathrm{~S} 2$ & $\mathrm{~S} 3$ & $\mathrm{~S} 4$ \\
\hline $\mathrm{LDPE}$ & $100 \%$ & $98.5 \%$ & $95.5 \%$ & $92.5 \%$ \\
\hline $\mathrm{Ag}$ & 0 & $1 \%$ & $3 \%$ & $5 \%$ \\
\hline $\mathrm{TiO}_{2}$ & 0 & $0.5 \%$ & $1.5 \%$ & $2.5 \%$ \\
\hline \multicolumn{5}{|c|}{ Weight (g) } \\
\hline $\mathrm{LDPE}$ & 100 & 94.42 & 91.42 & 88.42 \\
\hline $\mathrm{Ag}$ & 0 & 1 & 3 & 5 \\
\hline Tio 2 & 0 & 0.5 & 1.5 & 2.5 \\
\hline $\begin{array}{c}\text { Coupling } \\
\text { agent* }\end{array}$ & 0 & 4 & 4 & 4 \\
\hline $\begin{array}{c}\text { Irganox } \\
1010^{* *}\end{array}$ & 0 & 0.08 & 0.08 & 0.08 \\
\hline
\end{tabular}

* a material used to smooth the distribution of nano silver in polyethylene.** a white powder, a Phenolic primary antioxidant, which is an effective stabilizer for organic base materials to protects substrates against thermo-oxidative degradation.

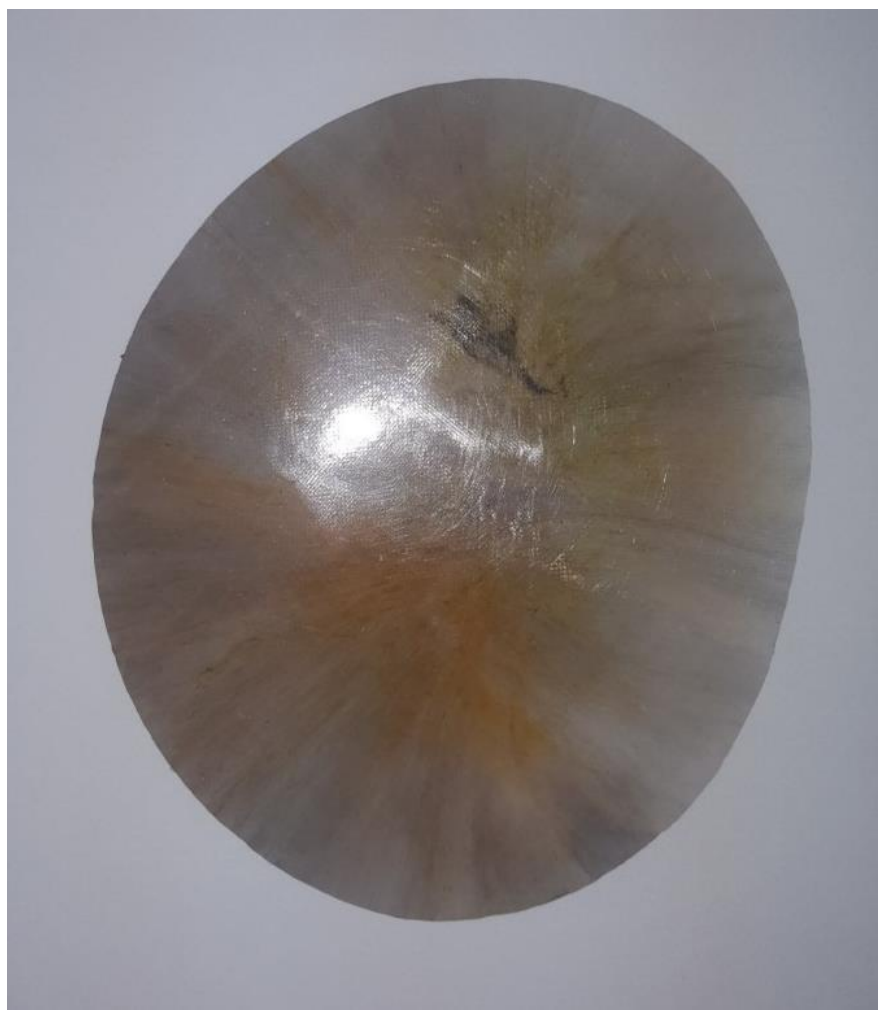

Fig. 1: The produced film from LDPE/TiO2/Ag NPs through the melt mixing method.

Titanium dioxide-silver nanocomposite film was prepared using different volumes of compounds (Table 2) according to the slight modified method of Rashedi, et al. [20]. Place $180 \mathrm{ml}$ of xylene in the erlenMeyer and place it on the heater to boil ( $145^{\circ} \mathrm{C}$ as boiling point). After 30 minutes, when Xylene was boiling, the LDPE was then weighed, slowly added and stirred with a magnet at a $250 \mathrm{rpm}$ for one hour. Nanosilver and titanium dioxide were weighed as done in the dark as possible and mixed using ultrasonic probe (Hielscher, UP200S with sonotrode S14, Germany) with a maximum output power of 400 $\mathrm{W}$ for proper mixing the nanoparticles. To prevent the sample became warm, the ultrasonic device was set at $25 \%$ of the maximum range and the time interval between wave pulses was set at 0.5 seconds. Also, a mixture of water and ice around the sample vessel was used to control the sample temperature and prevent solvent evaporation. The amount of $400 \mathrm{cc}$ of 
methanol as an anti-solvent solution was added to the mixture, and finally a rigid polymer was formed. Methanol was isolated from the polymer using filter paper and manganese (Fig 2). After 16 hours, to make $4 \mathrm{~g}$ of pressurized polymer, $4 \mathrm{gr}$ of final production weighed using filter paper to carry it. The weighed polymer of each treatment was placed on the central portion of each paper. For the initial heat treatment, the temperature of $160{ }^{\circ} \mathrm{C}$ with 3000 psi for 4 minutes was considered, and for the main pressure it was set to $160^{\circ} \mathrm{C}$ and 4000 psi for 3 minutes. The resulting film had shown no reaction or signs of burn (Fig 3).

Table 2: Percentage and weight of the film ingredients of 4 treatments used in Sol-Gel method.

\begin{tabular}{|l|l|l|l|}
\hline & \multicolumn{3}{|c|}{ Percent of purity } \\
\hline & $\mathrm{S} 5$ & $\mathrm{~S} 6$ & $\mathrm{~S} 7$ \\
\hline $\mathrm{LDPE}$ & $98.5 \%$ & $95.5 \%$ & $92.5 \%$ \\
\hline $\mathrm{Ag}$ & $1 \%$ & $3 \%$ & $5 \%$ \\
\hline $\mathrm{TiO}_{2}$ & $0.5 \%$ & $1.5 \%$ & $2.5 \%$ \\
\hline & \multicolumn{3}{|c|}{ Weight $(\mathrm{g})$} \\
\hline $\mathrm{LDPE}$ & 11.82 & 11.46 & 11.10 \\
\hline $\mathrm{Ag}$ & 0.12 & 0.36 & 0.6 \\
\hline Tio2 & 0.06 & 0.18 & 0.3 \\
\hline
\end{tabular}

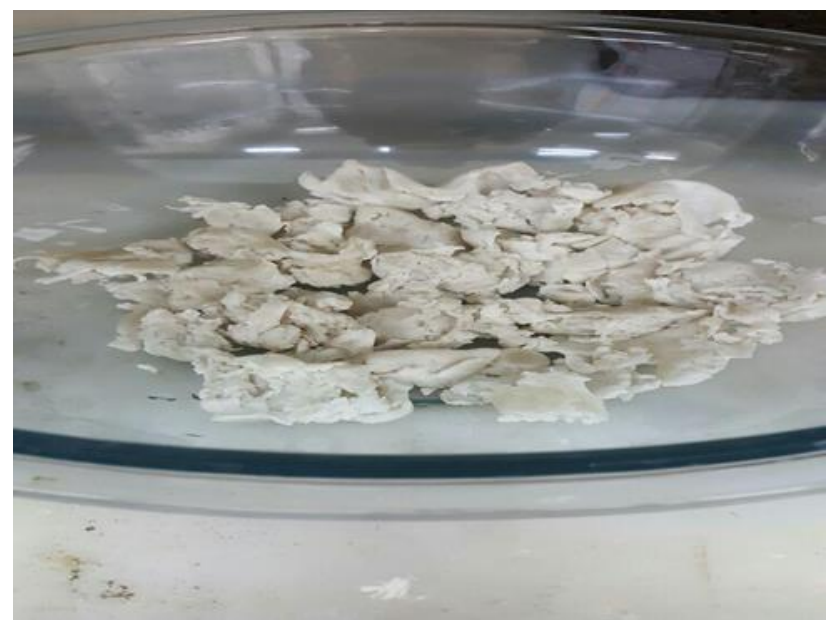

Fig. 2: The rigid polymer produced by sol-Gel method isolated from methanol.

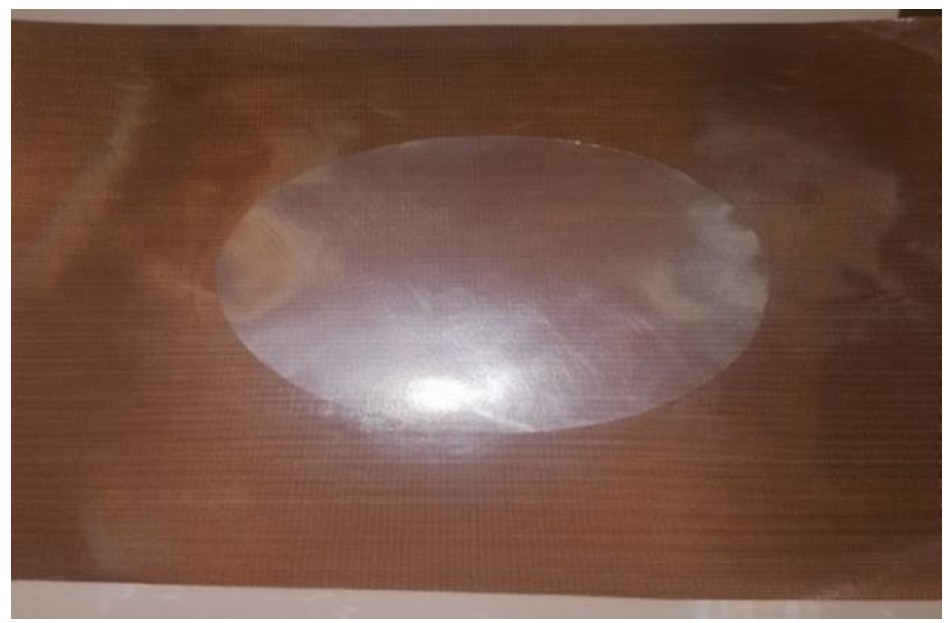


Fig. 3: The produced film from LDPE/TiO2/Ag NPs through the Sol-Gel method.

\subsection{Survey on Produced Film Features}

In order to observed the morphological characters of the produced films, the samples were observed directly by Field Emissi on Scanning Electron Microscope (FE-SEM) (S-4160, HITACHI, Japan) with a precision of 5 nm, a magnification of 20-30,000 and a maximum working voltage of $30 \mathrm{KV}$ was used. According to the method of Wang, et al. [5], the samples were completely cleaned and dried to obtain a high energy electron beam for imaging and chemical analysis. The samples were placed on stubs and performing an electrical contact between the stubs and samples was implemented.

\subsection{Bacterial Preparation and Antibacterial Disc Design}

Escherichia coli (ATCC 25922), Staphylococcus aureus, ATCC 6538 (candidates for gram-negative and positive bacteria, respectively), Aspergillus niger, ATCC 9142 (mold representative) and Candida albicans (10231) were cultured on a gradient nutrient agar tubes and kept at $4{ }^{\circ} \mathrm{C}$. During the preparation of liquid culture from the bacteria, a loop of each bacterial specimen was removed, cultured in sterilized conditions in $50 \mathrm{ml}$ of sterilized BHI medium, and then incubated at $37^{\circ} \mathrm{C}$ for $24 \mathrm{~h}$ in a shaking incubator. Ultimately, the dilution of microbial cultures was carried out with sterile distilled water to reach the suitable microbial population. During cultivation, the population was microbial (107 CFU / mL). Antimicrobial activity was determined using the disk diffusion method in an agar medium. Nano films prepared in different concentrations and methods were cut to $2 \mathrm{~cm}$ in diameter, placed in layers of filter papers and sterilized in incubator at 121 ${ }^{\circ} \mathrm{C}$ for 15 minutes [21]. Under strictly sterile conditions, prepared antibiogram discs were then transferred in to the MuellerHinton Agar medium, where the microbial agents were cultured in. Finally, the susceptibility of microbial strains to each treatment was determined using the diffusion disc method. Inhibition zone diameters was considered as antimicrobial index of each film deployed in this experiment [22].

\subsection{Fish-Sample Preparation}

Sander lucioperca with average of 2-4 kg were freshly purchased from a private sector in Mazandaran province, northern part of Iran and transferred to the Health Laboratory within less than 6 hours in an insulated container close to sufficient amounts of ice. The fish immediately were passed the peeling, evacuation, and gutting stages, and then fillets with dimensions of $5 \times 4 \times 5 \mathrm{~cm}$ cut. The fillets were completely washed with cold water until they were completely cleaned and the blood clots and other waste were removed. Then the prepared nanocomposite films were wrapped around the fish pieces and kept in a refrigerator for 20 days at $4{ }^{\circ} \mathrm{C}$. Fish were randomly assigned to conduct microbiological tests every 5 days [23].

\subsection{Microbial Tests for Fish Samples}

Samples were taken for microbiological tests according to the method of [24] and [25]. After preparing serial dilutions, $1 \mathrm{cc}$ of each dilution was inoculated to plate count agar. Plates were incubated for 48 hours at $37^{\circ} \mathrm{C}$ for aerobic mesophilic bacteria and 10 days at $7{ }^{\circ} \mathrm{C}$ for psychrophilic bacteria. In order to count the enterobacteriaceae bacteria, it was cultured on the medium of violet Red Bile Glucose Agar for 2 days at $30^{\circ} \mathrm{C}$, and finally colony count was done and recorded as log $\mathrm{CFU} / \mathrm{g}$.

\section{Statistical Analysis}

In order to determine the differences of Inhibition zone diameters $(\mathrm{mm})$ performed due to inoculation of $E$. coli, $S$. aureus, A. niger and $C$. albicans to the culture media in presence of discs produced by different ratio of LDPE/Ag/Tio2 nanocomposite films, One-Way ANOVA as well as Tukey's Bonferroni multiple comparisons test for pairwise differences was used $(\mathrm{p}<0.05)$. The data of colony count as $\log \mathrm{CFU} / \mathrm{g}$ for enterobacteriaceae, mesophilic and psychrophilic bacteria, was analyzed using a repeated measures for One-Way ANOVA through the general linear model procedure of SPSS version 16 (SPSS Inc., IL, USA) within 20 days while the fish samples were taken from the fillets every fifth day $(n=3)$.

\section{Results}

The result of Inhibition zone diameters for different nanocomposite LDPE/Ag/Tio2 against $E$. coli was listed in Table 3. The maximum Inhibition zone diameters $(\mathrm{mm})$ was observed in $\mathrm{S} 4(16.76 \pm .10)$, which significantly followed $(\mathrm{P}<0.05)$ by

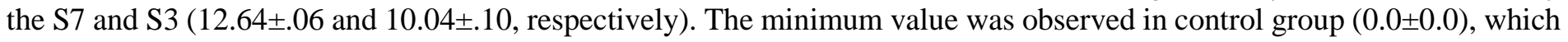




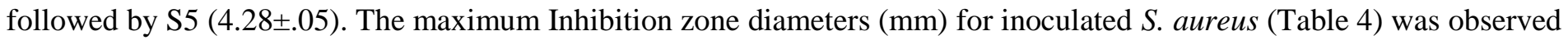

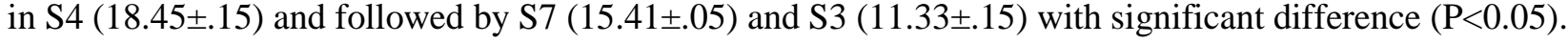

Table 3: Effect of different films on the Inhibition zone diameters (mm) of inoculated E. coli.

\begin{tabular}{|c|c|c|c|c|}
\hline & Method & Mean \pm SEM & Min. & Max. \\
\hline S1 (Control) & \multirow{4}{*}{$\begin{array}{l}\text { Melt } \\
\text { mixing }\end{array}$} & $0.0 \pm 0.0^{\mathrm{a}}$ & 0.00 & 0.00 \\
\hline S2 & & $4.60 \pm .10^{b}$ & 4.43 & 4.79 \\
\hline S3 & & $10.04 \pm .10^{c}$ & 9.84 & 10.17 \\
\hline S4 & & $16.76 \pm .10^{\mathrm{d}}$ & 16.61 & 16.94 \\
\hline S5 & \multirow{3}{*}{ Sol-Gel } & $4.28 \pm .05^{\mathrm{a}}$ & 4.22 & 4.37 \\
\hline S6 & & $8.46 \pm .10^{\mathrm{e}}$ & 8.37 & 8.59 \\
\hline S7 & & $12.64 \pm .06^{\mathrm{f}}$ & 12.58 & 12.77 \\
\hline
\end{tabular}

Table 4: Effect of different films on the Inhibition zone diameters (mm) of inoculated S. aureus.

\begin{tabular}{|l|l|l|l|l|}
\hline & Method & \multicolumn{1}{|c|}{ Mean \pm SEM } & Min. & Max. \\
\hline \multirow{3}{*}{ S1 (Control) } & & & & \\
\hline S2 & \multirow{3}{*}{ Melt } & $0.0 \pm 0.0^{\mathrm{a}}$ & 0.00 & 0.00 \\
\cline { 4 - 5 } & $4.86 \pm .07^{\mathrm{b}}$ & 4.74 & 4.97 \\
\cline { 4 - 5 } S3 & $11.33 \pm .15^{\mathrm{c}}$ & 11.11 & 11.61 \\
\hline S4 & & $18.45 \pm .15^{\mathrm{d}}$ & 18.27 & 18.75 \\
\hline S5 & $4.39 \pm .00^{\mathrm{e}}$ & 4.39 & 4.39 \\
\cline { 3 - 5 } S6 & & $10.24 \pm .03^{\mathrm{f}}$ & 10.18 & 10.29 \\
\hline Sol-Gel & & $15.41 \pm .05^{\mathrm{g}}$ & 15.32 & 15.47 \\
\hline
\end{tabular}

The result of Inhibition zone diameters for different nanocomposite LDPE/Ag/Tio2 against A. niger was listed in Table 5. The maximum Inhibition zone diameters $(\mathrm{mm})$ was observed in $\mathrm{S} 4(13.83 \pm .11)$, which significantly followed $(\mathrm{P}<0.05)$ by

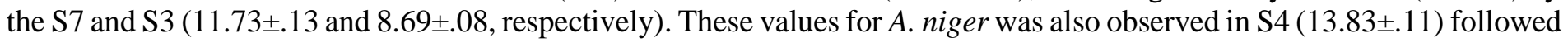
by $\mathrm{S} 7(11.73 \pm .13)$ with significant difference $(\mathrm{P}<0.05)$.

Table 5: Effect of different films on the Inhibition zone diameters (mm) of inoculated A. niger.

\begin{tabular}{|c|c|c|c|c|}
\hline & Method & Mean \pm SEM & Min. & Max. \\
\hline S1 (Control) & \multirow{4}{*}{$\begin{array}{l}\text { Melt } \\
\text { mixing }\end{array}$} & $0.0 \pm 0.0^{\mathrm{a}}$ & 0.00 & 0.00 \\
\hline $\mathrm{S} 2$ & & $3.61 \pm .00^{\mathrm{b}}$ & 3.61 & 3.61 \\
\hline S3 & & $8.69 \pm .08^{c}$ & 8.54 & 8.79 \\
\hline S4 & & $13.83 \pm .11^{\mathrm{d}}$ & 13.62 & 14.01 \\
\hline S5 & \multirow{3}{*}{ Sol-Gel } & $2.74 \pm .00^{\mathrm{e}}$ & 2.74 & 2.74 \\
\hline S6 & & $8.14 \pm .19^{c}$ & 7.94 & 8.52 \\
\hline S7 & & $11.73 \pm .13^{\mathrm{f}}$ & 11.52 & 11.96 \\
\hline
\end{tabular}

Table 6: Effect of different films on the Inhibition zone diameters (mm) of inoculated C. albicans. 


\begin{tabular}{|c|c|c|c|c|}
\hline & Method & Mean \pm SEM & Min. & Max. \\
\hline S1 (Control) & \multirow{4}{*}{$\begin{array}{c}\text { Melt } \\
\text { mixing }\end{array}$} & $0.0 \pm 0.0^{\mathrm{a}}$ & 0.00 & 0.00 \\
\hline S2 & & $3.97 \pm .06^{\mathrm{b}}$ & 3.88 & 4.08 \\
\hline S3 & & $8.28 \pm .00^{c}$ & 8.27 & 8.28 \\
\hline S4 & & $14.65 \pm .07^{\mathrm{d}}$ & 14.55 & 14.77 \\
\hline S5 & \multirow{3}{*}{ Sol-Gel } & $2.73 \pm .14^{\mathrm{e}}$ & 2.54 & 2.99 \\
\hline S6 & & $6.32 \pm .02^{\mathrm{f}}$ & 6.30 & 6.35 \\
\hline S7 & & $12.72 \pm .09^{\mathrm{g}}$ & 12.55 & 12.82 \\
\hline
\end{tabular}

\section{The Effect of Types of Films on the fillet shelf-life}

Based on the results gained due to the exposure of different types of LDPE nanocomposite films on shelf-life of fish fillet, the minimum marginal mean value of the mesophilic bacteria $(2.67 \pm 0.08, \log \mathrm{CFU} / \mathrm{g})$ was occurred in S4 at the 5 day of the experiment, of which significantly $(\mathrm{P}<0.05)$ less than those of other treatments and control. This value was followed by those of the groups of $\mathrm{S} 2$ and $\mathrm{S} 7(3.03 \pm 0.08,3.06 \pm 0.08)$, respectively with no significant difference $(\mathrm{P}>0.05)$. The stability of the value (Fig. 4) for S4 (3.26 \pm 0.06$)$ was continued (as minimum value) until 10th day of the experiment. This value was followed by that of S7 (3.52 \pm 0.06$)$. At the 15th day, the minimum marginal mean value of the log CFU/g of mesophilic bacteria was $5.20 \pm 0.12$ with remarkable significant difference $(\mathrm{P}<0.05)$ compared with those of other groups, of which the second minimum one was $6.23 \pm 0.12$ in S7 and followed by S3 (6.27 \pm 0.12$)$. This trend was continued until 20 ${ }^{\text {th }}$ day (Fig. 4) so that the minimum value for mesophilic bacteria was observed in $\mathrm{S} 4$ as $6.25 \pm 0.15$ with significant differences $(\mathrm{P}<0.05)$ against other groups.

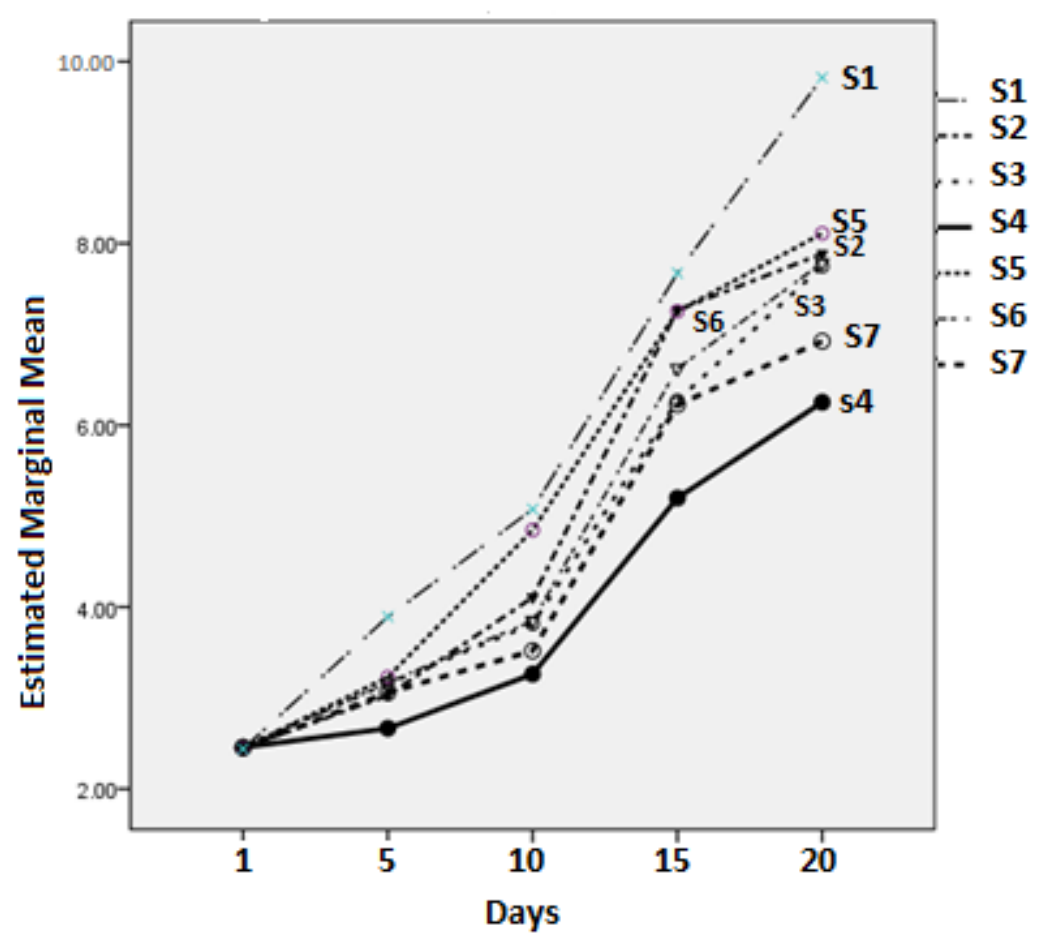

Fig. 4: Estimation of Marginal Means as Log CFU/g of mesophilic bacteria through the interaction of Film type $\times$ Time of measurement.

Based on the results gained for the Enterobacteriacea, the minimum marginal mean value of the bacteria was observed at the $5^{\text {th }}$ day $(2.07 \pm 0.06, \log$ CFU/g) in S7 and followed by S6, S3 and S4 (2.14 $\pm 0.06,2.14 \pm 0.06$ and 2.17 \pm 0.06 , respectively) with no significant difference $(\mathrm{P}>0.05)$ to each other. All the values showed less values compared with control $(\mathrm{P}<0.05)$. At 
the $10^{\text {th }}$ day, the minimum marginal mean value of the Enterobacteriacea $(2.26 \pm 0.10, \log \mathrm{CFU} / \mathrm{g})$ was observed in S5 and followed by those of $\mathrm{S} 4(2.31 \pm 0.10, \log \mathrm{CFU} / \mathrm{g})$ with no significant difference (P>0.05). S6 and S7 (2.54 \pm 0.10 and $2.54 \pm 0.10$, respectively) with significant difference $(\mathrm{P}<0.05)$ compared with former values showed the subsequent ones. This pattern was agitated on $15^{\text {th }}$ day (Fig. 5) so that the minimum marginal mean value of the bacteria was observed in S4 $(2.59 \pm 0.08)$ and followed by S7 and S3 $\left(2.89 \pm 0.08\right.$ and $2.95 \pm 0.08$, respectively). On $20^{\text {th }}$ day, the minimum value kept for S4 (3.83 \pm 0.06$)$ with remarkable distance to the next one observed in S7 (4.31 \pm 0.08$)$, which showed significant difference $(\mathrm{P}<0.05)$ against other groups.

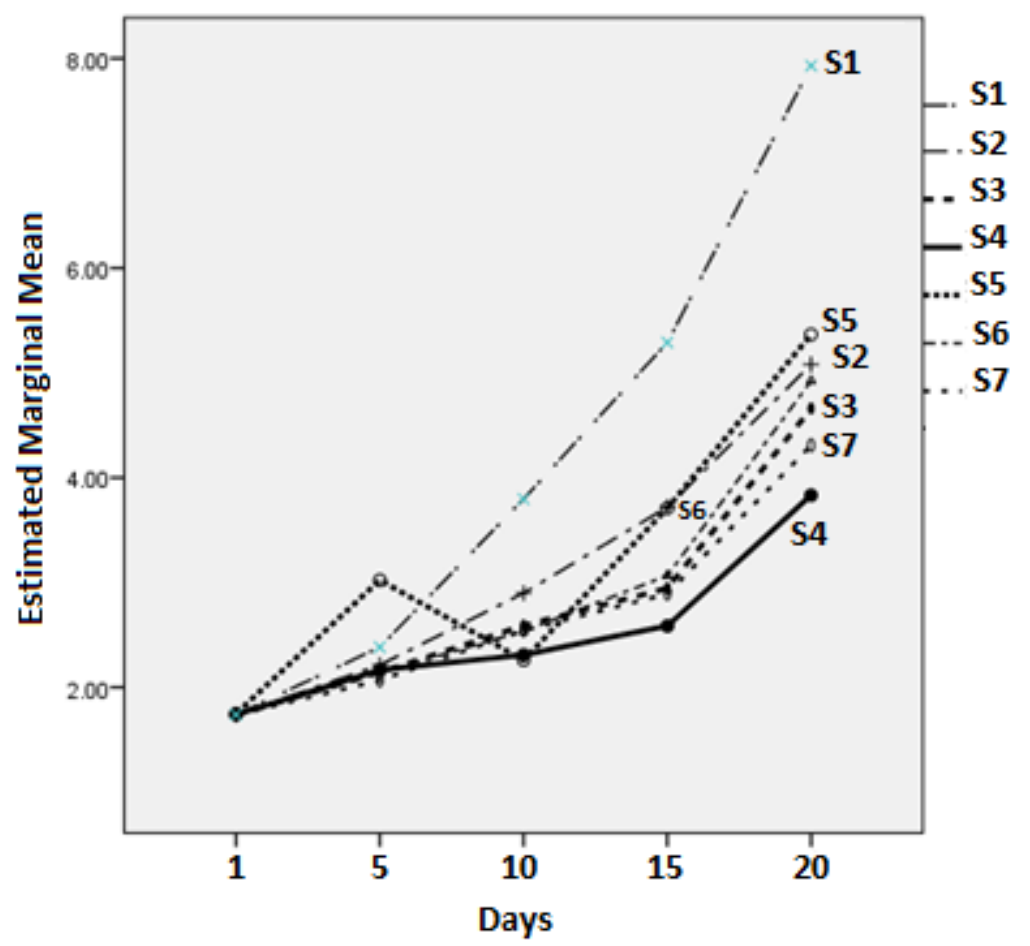

Fig. 5: Estimation of Marginal Means as Log CFU/g of Enterobacteriaceae bacteria through the interaction of Film type $\times$ Time of measurement.

According to the results of psychrophilic bacteria (Fig. 6), the minimum marginal mean value of the bacteria was observed at the $5^{\text {th }}$ day $(3.79 \pm 0.03, \log \mathrm{CFU} / \mathrm{g})$ in $\mathrm{S} 4$ and followed by $\mathrm{S} 3(4.11 \pm 0.15)$ with significant difference $(\mathrm{P}<0.05)$. All the values showed less values compared with control $(\mathrm{P}<0.05)$. At the $10^{\text {th }}$ day, the minimum marginal mean value of the Enterobacteriacea $(4.00 \pm 0.03, \log \mathrm{CFU} / \mathrm{g})$ was observed in $\mathrm{S} 4$ and followed by that of $\mathrm{S} 7(4.52 \pm 0.03, \log \mathrm{CFU} / \mathrm{g})$ with significant difference $(\mathrm{P}<0.05)$. This pattern on $15^{\text {th }}$ day (Fig. 6) showed that the minimum marginal mean value of the bacteria was observed in S4 (4.87 \pm 0.15$)$ and followed by S7 $(5.11 \pm 0.1)$. On $20^{\text {th }}$ day, the minimum value kept for S4 $(5.54 \pm 0.15)$ with significant difference to the others $(\mathrm{P}<0.05)$. 


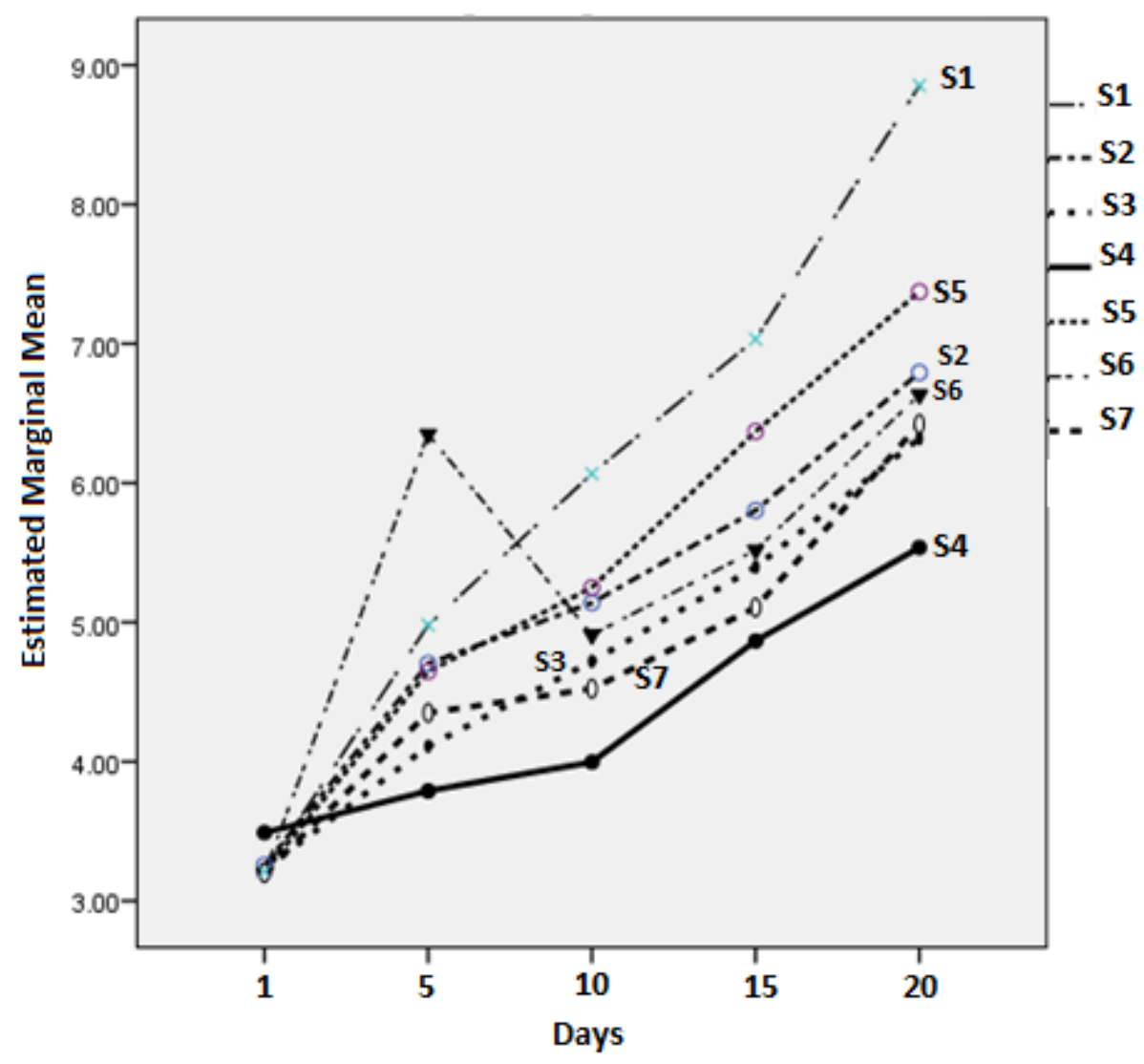

Fig. 6: Estimation of Marginal Means as Log CFU/g of psychrophilic bacteria through the interaction of Film type $\times$ Time of measurement.

\section{Conclusion}

The film produced by the melt mixing method with $5 \mathrm{wt} . \%$ Silver and $2.5 \mathrm{wt} . \%$ Titanium dioxide decreased significantly (0.05> P) shows the logarithmic growth rate of aerobic mesophilic bacteria, Cold and Enterobacteriaceae.

\section{References}

[1] J. H. Han, Innovations in food packaging. Academic Press, 2005.

[2] S. Mihindukulasuriya and L.-T. Lim, "Nanotechnology development in food packaging: A review," Trends in Food Science \& Technology, vol. 40, no. 2, pp. 149-167, 2014.

[3] R. Tharanathan, "Biodegradable films and composite coatings: past, present and future," Trends in Food Science \& Technology, vol. 14, no. 3, pp. 71-78, 2003.

[4] J. Zhang, X. Wang, L. Lu, D. Li, and X. Yang, "Preparation and performance of high-impact polystyrene (HIPS)/nano$\mathrm{TiO} 2$ nanocomposites," Journal of applied polymer science, vol. 87, no. 3, pp. 381-385, 2003.

[5] Z. Wang, G. Li, G. Xie, and Z. Zhang, "Dispersion behavior of TiO2 nanoparticles in LLDPE/LDPE/TiO2 nanocomposites," Macromolecular Chemistry and Physics, vol. 206, no. 2, pp. 258-262, 2005.

[6] J. S. Park, J. H. Kim, Y. C. Nho, and O. H. Kwon, "Antibacterial activities of acrylic acid-grafted polypropylene fabric and its metallic salt," Journal of applied polymer science, vol. 69, no. 11, pp. 2213-2220, 1998.

[7] L. Zan, W. Fa, and S. Wang, "Novel Photodegradable Low-Density Polyethylene- TiO2 Nanocomposite Film," Environmental science \& technology, vol. 40, no. 5, pp. 1681-1685, 2006.

[8] J.-G. Yu, H.-G. Yu, B. Cheng, X.-J. Zhao, J. C. Yu, and W.-K. Ho, "The effect of calcination temperature on the surface microstructure and photocatalytic activity of TiO2 thin films prepared by liquid phase deposition," The Journal of Physical Chemistry B, vol. 107, no. 50, pp. 13871-13879, 2003. 
[9] M. Cho, H. Chung, W. Choi, and J. Yoon, "Linear correlation between inactivation of E. coli and OH radical concentration in TiO 2 photocatalytic disinfection," Water research, vol. 38, no. 4, pp. 1069-1077, 2004.

[10] C. Chawengkijwanich and Y. Hayata, "Development of TiO 2 powder-coated food packaging film and its ability to inactivate Escherichia coli in vitro and in actual tests," International journal of food microbiology, vol. 123, no. 3, pp. 288-292, 2008.

[11] A. Mihaly Cozmuta et al., "Active packaging system based on $\mathrm{Ag} / \mathrm{TiO} 2$ nanocomposite used for extending the shelf life of bread. Chemical and microbiological investigations," Packaging technology and science, vol. 28, no. 4, pp. 271-284, 2015.

[12] H. Ahari, S. Farokhi, S. Moradi, and A.-A. Anvar, "Effect of Nano packaging containing Ag-Tio2 in inactivating the selected bacteria experimentally exposed to the chicken-eggshell."

[13] J. P. Ruparelia, A. K. Chatterjee, S. P. Duttagupta, and S. Mukherji, "Strain specificity in antimicrobial activity of silver and copper nanoparticles," Acta biomaterialia, vol. 4, no. 3, pp. 707-716, 2008.

[14] F. Martinez-Gutierrez et al., "Synthesis, characterization, and evaluation of antimicrobial and cytotoxic effect of silver and titanium nanoparticles," Nanomedicine: Nanotechnology, Biology and Medicine, vol. 6, no. 5, pp. 681-688, 2010.

[15] N. Stobie et al., "Prevention of Staphylococcus epidermidis biofilm formation using a low-temperature processed silver-doped phenyltriethoxysilane sol-gel coating," Biomaterials, vol. 29, no. 8, pp. 963-969, 2008.

[16] Q. Feng, J. Wu, G. Chen, F. Cui, T. Kim, and J. Kim, "A mechanistic study of the antibacterial effect of silver ions on Escherichia coli and Staphylococcus aureus," Journal of biomedical materials research, vol. 52, no. 4, pp. 662-668, 2000.

[17] M. Yamanaka, K. Hara, and J. Kudo, "Bactericidal actions of a silver ion solution on Escherichia coli, studied by energy-filtering transmission electron microscopy and proteomic analysis," Applied and environmental microbiology, vol. 71, no. 11, pp. 7589-7593, 2005.

[18] S. Jones, H. Ahonen, L. Granlund, T. Arsiola, and J. Taskinen, "Two Novel Microsporidia in Skeletal Muscle of PikePerch Sander lucioperca and Burbot Lota lota in Finland," Journal of Parasitology, vol. 103, no. 1, pp. 95-102, 2017.

[19] W. L. Oliani et al., "Preparation and Characterization of Polyethylene Nanocomposites with Clay and Silver Nanoparticles," in Characterization of Minerals, Metals, and Materials 2017: Springer, 2017, pp. 709-718.

[20] H. Rashedi, A. Partovi, R. Fattah, and M. Khiabani, "The Effect of Silver Nanofilms based on Titaniom Dioxide on the Shelf-life of Rainbow Trout Fillet (Oncorhynchus mykiss)," Iranian Journal of Nutrition Sciences \& Food Technology, vol. 11, no. 3, pp. 85-92, 2016.

[21] J. Mikiciuk, E. Mikiciuk, and A. Szterk, "Physico-Chemical Properties and Inhibitory Effects of Commercial Colloidal Silver Nanoparticles as Potential Antimicrobial Agent in the Food Industry," Journal of Food Processing and Preservation, vol. 41, no. 2, 2017.

[22] M. Saadatmand, M. Yazdanshenas, S. Rezaei Zarchi, B. Yosefi Talori, and M. Negahdari, "The antimicrobial activity of chitosan nanocomposite-TiO2, and its application on the gauze hospital," Laboratory J, vol. 6, no. 1, pp. 57-9, 2012.

[23] A. S. Duun and T. Rustad, "Quality of superchilled vacuum packed Atlantic salmon (Salmo salar) fillets stored at1.4 and-3.6 C," Food Chemistry, vol. 106, no. 1, pp. 122-131, 2008.

[24] K. I. Sallam, "Antimicrobial and antioxidant effects of sodium acetate, sodium lactate, and sodium citrate in refrigerated sliced salmon," Food control, vol. 18, no. 5, pp. 566-575, 2007.

[25] S. M. Ojagh, M. Rezaei, S. H. Razavi, and S. M. H. Hosseini, "Effect of chitosan coatings enriched with cinnamon oil on the quality of refrigerated rainbow trout," Food chemistry, vol. 120, no. 1, pp. 193-198, 2010. 